\title{
BMI is an important driver of $\beta$-cell loss in type 1 diabetes upon diagnosis in 10 to 18-year-old children
}

\author{
A Lauria ${ }^{1, *}$, A Barker ${ }^{2, *}$, N Schloot ${ }^{3,+}$, N Hosszufalusi ${ }^{4}$, J Ludvigsson ${ }^{5}$, C Mathieu $^{6}$, \\ D Mauricio7, M Nordwall, ${ }^{5,8}$, B Van der Schueren ${ }^{6}$, T Mandrup-Poulsen ${ }^{9,14}$, \\ W A Scherbaum ${ }^{10}$, I Weets ${ }^{11,12}$, F K Gorus ${ }^{11,12}$, N Wareham ${ }^{2}$, R D Leslie ${ }^{13}$ and \\ P Pozzilli ${ }^{1,13}$
}

\begin{abstract}
${ }^{1}$ Department of Endocrinology and Diabetes, University Campus Bio-Medico, Via Alvaro del Portillo, Rome 21 00128, Italy, ${ }^{2}$ MRC Epidemiology Unit, Cambridge, UK, ${ }^{3}$ Institute for Clinical Diabetology, German Diabetes Centre, Leibniz-Institute for Diabetes Research and Clinic for Metabolic Diseases Heinrich Heine University, Dusseldorf, Germany, ${ }^{4}$ Semmelweis University, 3rd Department of Internal Medicine, Linkoping University, Linkoping, Sweden, ${ }^{5}$ Division of Pediatrics, Department of Clinical and Experimental Medicine, Faculty of Health Sciences, Linköping University, Linköping, Sweden, ${ }^{6}$ Laboratory for Experimental Medicine and Endocrinology, Katholieke Universiteit Leuven, Leuven, Belgium, ${ }^{7}$ Department Endocrinology, Hospital Arnau de Vilanova, Lleida, Spain, ${ }^{8}$ Pediatric Clinic, Vrinnevi Hospital, Norrköping, Sweden, ${ }^{9}$ Department of Biomedical Sciences, University of Copenhagen, Copenhagen, Denmark, ${ }^{10}$ Department of Endocrinology, Diabetes and Rheumatology, Heinrich Heine University, Dusseldorf, Germany, ${ }^{11}$ Diabetes Research Center and Academic Hospital (UZ Brussel), Vrije Universiteit Brussel (VUB), Brussel, Belgium, ${ }^{12}$ Belgian Diabetes Registry (BDR), Brussels, Belgium, ${ }^{13}$ Centre of Diabetes, Blizard Institute, Barts and The London School of Medicine, Queen Mary University of London, London, UK and ${ }^{14}$ Department of Molecular Medicine and Surgery, Karolinska Institutet, Stockholm, Sweden

*(A Lauria and A Barker contributed equally to this work)

${ }^{\dagger} \mathrm{N}$ Schloot is now at Lilly Germany GmbH, BU Diabetes Medical, Dusseldorf, Germany
\end{abstract}

Correspondence should be addressed to P Pozzilli

Email

p.pozzilli@unicampus.it

\begin{abstract}
Objective: Body weight-related insulin resistance probably plays a role in progression to type 1 diabetes, but has an uncertain impact following diagnosis. In this study, we investigated whether BMI measured at diagnosis was an independent predictor of C-peptide decline 1-year post-diagnosis.

Design: Multicentre longitudinal study carried out at diagnosis and up to 1-year follow-up.

Methods: Data on C-peptide were collected from seven diabetes centres in Europe. Patients were grouped according to age at diagnosis ( $<5$ years, $n=126 ;>5$ years $<10$ years, $n=295 ;>10$ years $<18$ years, $n=421 ;>18$ years, $n=410$ ). Linear regression was used to investigate whether BMI was an independent predictor of change in fasting C-peptide over 1 year. Models were additionally adjusted for baseline insulin dose and HbA1c.

Results: In individuals diagnosed between 0 and 5 years, 5 and 10 years and those diagnosed $>18$ years, we found no association between BMI and C-peptide decline. In patients aged 10-18 years, higher BMI at baseline was associated with a greater decline in fasting C-peptide over 1 year with a decrease $\left(\beta 95 \% \mathrm{Cl} ; P\right.$ value) of $0.025(0.010,0.041) \mathrm{nM} / \mathrm{kg}$ per $\mathrm{m}^{2}$ higher baseline $\mathrm{BMI}(P=0.001)$. This association remained significant after adjusting for gender and differences in $\mathrm{HbA} 1 \mathrm{c}$ and insulin dose $(\beta=0.026,95 \% \mathrm{Cl}=0.0097,0.042 ; P=0.002)$.

Conclusions: These observations indicate that increased body weight and increased insulin demand are associated with more rapid disease progression after diagnosis of type 1 diabetes in an age group 10-18 years. This should be considered in studies of $\beta$-cell function in type 1 diabetes.
\end{abstract}




\section{Introduction}

Type 1 diabetes is considered an autoimmune disorder caused by inflammatory $\beta$-cell destruction, and presenting in childhood is characterised by loss of weight, ketoacidosis, acute onset and insulin dependency. In contrast, type 2 diabetes is considered a metabolic disorder usually presenting in adults, associated with obesity and insulin resistance (1).

However, insulin resistance may influence disease progression following diagnosis also in type 1 diabetes. Yki-Jarvinen \& Koivisto (2) showed that newly diagnosed type 1 diabetes patients who went into remission of insulin therapy had greater insulin sensitivity than patients who continued to require insulin therapy. In addition, they found that more than a year post-diagnosis, insulin sensitivity in these patients was associated with body weight and was significantly reduced (2). Ludvigsson et al. (3) described in a national cohort of patients with type 1 diabetes that those with higher BMI had higher C-peptide at diagnosis, but then lost relatively more C-peptide during the first years after diagnosis.

The concept that insulin resistance may play a key role in the aetiology of type 1 diabetes is described by the accelerator hypothesis (4) and by the wider $\beta$-cell stress hypothesis (5).

The accelerator hypothesis argues that type 1 and type 2 diabetes are disorders that are aggravated by increased insulin resistance due to body weight gain, set against different genetic backgrounds, with the autoimmunity of type 1 diabetes being an expected response to upregulated $\beta$-cell response in individuals with genetic predisposition to heightened immunoreactivity.

Support for this hypothesis comes from a number of sources. In addition to the increase in incidence of type 2 diabetes that has paralleled increase in obesity, there has been an equally striking rise in the incidence of type 1 diabetes (6). Rapid weight gain during the first years of life has been found to increase the incidence of type 1 diabetes (7) and a number of studies have also shown a positive correlation between the year of onset of type 1 diabetes and BMI $(8,9,10)$. More recently, we have shown that the decline in fasting C-peptide is more rapid in those patients with an earlier age of onset of type 1 diabetes, and that the factors influencing the decline in fasting C-peptide following diagnosis differ substantially according to the age of onset (11). Several studies have reported data showing that the age of onset of type 1 diabetes is inversely related with BMI, with children diagnosed at younger ages typically being heavier than those diagnosed later $(9,12,13,14)$. Genetic studies have demonstrated that the proportion of high-risk HLA haplotypes has declined over time and been replaced by protective HLA haplotypes, arguing that the environmental contribution to disease risk (i.e. insulin resistance associated with increased obesity) has become more prominent in type 1 diabetes aetiology alongside the secular trends in obesity $(15,16)$. Finally, several studies indicate that in individuals at risk for the development of type 1 diabetes, insulin resistance is an independent risk factor for disease development $(17,18,19,20)$, and in studies of identical twins the co-twin who goes on to develop type 1 diabetes is more insulin resistant than the twin who does not (21). However it is important to add that other studies question these findings, and hence the theory is controversial (22).

Although some of the evidence summarised above suggests a potential key role for insulin resistance in type 1 diabetes aetiology, there has been no direct demonstration that insulin resistance in type 1 diabetes is detrimental to $\beta$-cell function even though, as mentioned above, it has been shown that $\mathrm{C}$-peptide decline is more rapid in type 1 diabetic patients with higher BMI (3).

In order to investigate whether body weight influences loss of C-peptide in type 1 diabetes, we have investigated the association between BMI measured at age of onset and change in fasting C-peptide levels in the first year post-diagnosis using longitudinal data from a large data set of European type 1 diabetes patients recruited from seven different centres.

\section{Subjects and methods}

\section{Subjects}

From a cohort of 3929 Caucasian patients with type 1 diabetes of seven European registries (Belgian Diabetes Registry, Leuven Database, Hungary Database, Spain Database, Sweden Database, Germany Database, Italy Database IMDIAB), we included 1252 patients for whom data on fasting C-peptide, BMI, HbA1c levels and insulin dose at baseline and additionally for fasting C-peptide at 1 year follow-up were available. Eighty-one patients were placebo-treated subjects from immune intervention trails. In each study centre, type 1 diabetes was diagnosed according to ADA and WHO criteria. A detailed description of the cohort has been published elsewhere (11). 


\section{Measurements}

Fasting, stimulated C-peptide and HbA1c were measured by standardised assays at each centre after an overnight pause in long-acting insulin; fasting glucose was required to be $70-200 \mathrm{mg} / \mathrm{dl}$ at the time of sampling. Baseline C-peptide was measured within the first 12 weeks since initiation of insulin therapy. Different methods were used for C-peptide determination, but all had similar detection limit $(0.01 \mathrm{nM})$, and each centre covered patients of different age groups. Weight and height were measured using standardised procedures and used to calculate BMI (weight/height ${ }^{2}$ ).

\section{Statistical methods}

Statistical analysis was performed with Stata 11.2 (StataCorp. 2009, Stata Statistical Software: Release 11.2, TX, USA). Participants were stratified into four groups according to their age at onset of type 1 diabetes: very young ( $\leq 5$ years), pre-pubertal ( $>5$ and $\leq 10$ years), pubertal ( $>10$ and $\leq 18$ years) and adult (18-65 years), and all analyses were performed for the whole study population and for each group.

To investigate the influence of BMI on change in fasting C-peptide over 1 year ( $\Delta$ C-peptide ${ }_{0-1}$ ), linear regression models were used with change in fasting C-peptide (C-peptide Year-1 $_{1}-\mathrm{C}$-peptide baseline ) as an outcome variable and baseline BMI as the independent variable of interest. The models were adjusted for change in BMI over 1 year $(\Delta \mathrm{BMI}-1)$ for subjects with available data about BMI after 1 year from the diagnosis $(n=780)$. The models were further adjusted for age of onset, sex, baseline HbA1c and baseline insulin dose to investigate whether differences in these variables explained any observed association between BMI and $\Delta$ C-peptide ${ }_{0-1}$. $\Delta$ C-peptide ${ }_{0-1}$ was included in models as an untransformed variable since data were normally distributed. All models were also further adjusted for study centre to account for potential differences in the method of measurement of C-peptide and HbA1c.

In addition to analysing data using untransformed BMI variables, for children in the 0-5, 5-10 and 10-18 year age groups, we also performed regression analysis with BMI transformed to $Z$-scores by the least mean squares (LMS) method (23) using the 1990 British Growth reference (zanthro command in Stata), which accounts for the fact that differences in BMI between children of different ages can be a result of differences in growth and development rather than solely adiposity. However, since the use of untransformed BMI or BMI z-scores did not alter our results, data are reported for untransformed BMI variables given the ease of interpretation and comparison with results in adults. Finally, potential interactions between baseline variables were investigated by fitting continuous interactions terms in regression models.

To maximise the sample size, we report analyses that are not restricted to those with non-missing values for all parameters of interest (BMI, gender, HbA1c and insulin dose), and hence the sample size for each regression model is slightly different. However, the results were not different when we performed sensitivity analysis focusing solely on individuals with non-missing values for all traits.

\section{Results}

Baseline characteristics of study participants according to age of onset are given in Table 1.

\section{Association of BMI with change in fasting C-peptide over 1 year $\left(\Delta C\right.$-peptide $\left.{ }_{0-1}\right)$ in the total cohort}

At baseline, individuals with a higher BMI had higher fasting C-peptide levels with a $5.2 \%(4.0,6.5)$ increase per $1 \mathrm{~kg} / \mathrm{m}^{2}$ higher BMI $\left(P=3.3 \times 10^{-16}\right)$.

Individuals with a higher BMI at baseline had a greater decline in $\Delta$ C-peptide ${ }_{0-1}$ with each $1 \mathrm{~kg} / \mathrm{m}^{2}$ higher BMI associated with a decrease ( $\beta$ 95\% CI; $P$ value) of -0.012 $(-0.020,-0.0046 ; 0.0002) \mathrm{nM}$ in fasting C-peptide. This association remained significant after taking into account the differences in baseline HbA1c levels $(P=0.012)$ and $\Delta$ BMI0-1 $(P=0.026)$, but not when variation in baseline insulin dose $(P=0.060)$ or both HbA1c levels and insulin dose $(P=0.11)$ was controlled.

\section{Association of BMI with change in fasting C-peptide over 1 year ( $\Delta C$-peptide $\left.{ }_{0-1}\right)$ by age group}

At baseline, differences in BMI were not associated with fasting $C$-peptide in those diagnosed at $\leq 5$ years $(P=0.45)$. In those diagnosed between 5 and 10 years, a larger BMI at baseline was significantly associated with greater fasting C-peptide levels, with each $1 \mathrm{~kg} / \mathrm{m}^{2}$ higher BMI associated with a $4.8 \%(2.1,7.5)$ increase in fasting C-peptide $(P=0.00052)$.

BMI was not a predictor of $\Delta$ C-peptide ${ }_{0-1}$ in those diagnosed at $\leq 5$ years $(\beta=0.003,95 \% \mathrm{CI}=-0.022,0.027$; $P=$ NS) or those diagnosed between 5 and 10 years of age $(\beta=0.011,95 \% \mathrm{CI}=-0.0030,0.026 ; P=\mathrm{NS})$. 
Table 1 Characteristics of population by age of onset. Data are mean \pm s.D.

\begin{tabular}{|c|c|}
\hline Characteristic & Total cohort \\
\hline$n(\mathrm{~m} / \mathrm{f})$ & $1252(752 / 500)$ \\
\hline Age of onset (years) & $16.7(10.6)$ \\
\hline BMI $\left(k g / m^{2}\right)$ & $18.8(3.9)$ \\
\hline BMI $z$-score for age & $-0.40(1.3)$ \\
\hline Insulin dose (IU/kg per day) & $0.66(0.37)$ \\
\hline HbA1c (\%) & $10.3(3.0)$ \\
\hline Fasting C-peptide (nM) & $0.31(0.37)$ \\
\hline
\end{tabular}

\begin{tabular}{|c|c|}
\hline & Age at diag \\
\hline$\leq 5$ & $>5$ and $\leq 10$ \\
\hline $126(79 / 47)$ & $295(156 / 139)$ \\
\hline $3.2(1.5)$ & $8.2(1.4)$ \\
\hline $15.3(2.3)$ & $16.1(2.7)$ \\
\hline$-1.1(1.9)$ & $-0.26(1.3)$ \\
\hline $0.86(0.50)$ & $0.70(0.34)$ \\
\hline $9.9(2.4)$ & $9.9(2.9)$ \\
\hline $0.16(0.21)$ & $0.21(0.27)$ \\
\hline
\end{tabular}

nosis (years)

\begin{tabular}{l}
$>10$ and $\leq 18$ \\
\hline $421(257 / 164)$ \\
$13.4(2.1)$ \\
$18.7(3.1)$ \\
$-0.31(1.1)$ \\
$0.71(0.35)$ \\
$10.0(3.2)$ \\
$0.33(0.40)$ \\
\hline
\end{tabular}

\begin{tabular}{c}
\multicolumn{1}{c}{$>18$} \\
\hline $410(260 / 150)$ \\
$29.3(7.4)$ \\
$22.0(3.4)$ \\
$-0.40(1.3)$ \\
$0.51(0.30)$ \\
$11.0(2.8)$ \\
$0.41(0.41)$ \\
\hline
\end{tabular}

At baseline, in individuals diagnosed between 10 and 18 years, a higher BMI was associated with higher fasting C-peptide levels with a $3.3 \%(0.98,5.6)$ increase per $1 \mathrm{~kg} / \mathrm{m}^{2}$ difference in BMI $(P=0.0054)$.

In individuals diagnosed between 10 and 18 years, a higher BMI at baseline was associated with a greater decline in fasting $\mathrm{C}$-peptide over 1 year with a decrease of $-0.025(-0.010,-0.041 ; 0.001) \mathrm{nM}$ for each $1 \mathrm{~kg} / \mathrm{m}^{2}$ higher baseline BMI. This association remained significant even after differences in baseline $\mathrm{HbA1c}$, and insulin dose were taken into account $(\beta=-0.026,95 \% \mathrm{CI}=-0.0097$, $-0.042 ; P=0.002)$. Data on BMI 1 year after the diagnosis were available for 264 subjects. In these subjects, the association between baseline BMI and the decline in $\mathrm{C}$-peptide remained significant also after adjustment for $\Delta \mathrm{BMI}_{0-1}(\beta=-0.028,95 \% \mathrm{CI}=-0.0049,-0.006$; $P=0.012)$. The detrimental effect of increased BMI at baseline was reduced in those individuals with a larger baseline insulin dose $\left(p_{\text {interaction }}=0.004\right)$.

In individuals diagnosed at $>18$ years, each $1 \mathrm{~kg} / \mathrm{m}^{2}$ higher BMI was associated with a $5.4 \%(3.3,7.4)$ increase in fasting C-peptide $\left(P=5.0 \times 10^{-7}\right)$; however, baseline BMI was not a significant predictor of $\Delta$ C-peptide $e_{0-1}$.

The association between changes in BMI and $\Delta$ C-peptide ${ }_{0-1}$ in different age of onset groups is shown in Fig. 1.

Inclusion of BMI $Z$-scores in regression models of individuals diagnosed at $<18$ years of age (in place of untransformed BMI) did not alter the results.

\section{Discussion}

This study demonstrates that increased BMI is associated with an accelerated rate of fasting C-peptide decline over 1 year in newly diagnosed type 1 diabetes patients aged 10-18 years. It is assumed that insulin resistance may play a role in the pathophysiology or progression to type 1 diabetes, and the results reported here suggest that, in those diagnosed with an age of onset of between 10 and 18 years, decreased insulin sensitivity may play an important role for residual C-peptide after diagnosis.

Although increasing insulin secretion strives to maintain normal glucose tolerance in response to reductions in insulin sensitivity, the increased secretory demand in insulin resistant states can potentially be detrimental to $\beta$-cell function, possibly due to $\beta$-cell dysfunction resulting from the excessive stimulation of $\beta$-cells necessary for the maintenance of normoglycaemia in insulin-resistant states $(24,25,26)$.

It is well known that a greater BMI is associated with reduction in insulin sensitivity $(26,27)$, and hence the greater rate of decline of C-peptide in patients with a higher BMI could plausibly result from $\beta$-cell exhaustion by the mechanism described previously.

An important question to be addressed is why the detrimental association of BMI with fasting C-peptide decline is observed only in those individuals aged 10-18 years. A likely explanation is the pubertal transition that occurs during this age range. A previous longitudinal study has shown that during puberty there is a transient decrease in insulin sensitivity, and hence the pubertal transition is an example of an insulin-resistant state (28).

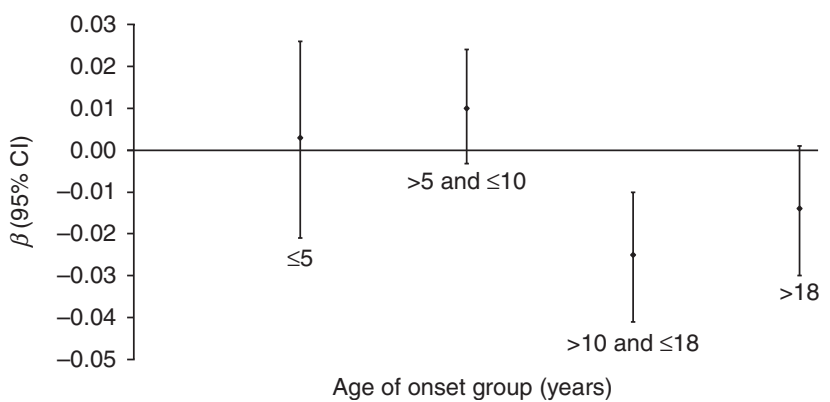

\section{Figure 1}

Association between $1 \mathrm{~kg} / \mathrm{m}^{2}$ change in BMI and $\Delta$ C-peptide ${ }^{0-1}$ in age of onset and sex-adjusted models by age of onset group. 
The lack of association between BMI and fasting $\mathrm{C}$-peptide decline over 1 year in younger and older age groups may be due to the fact that $\beta$-cell dysfunction is much more severe in the former and much less severe in the latter $(29,30,31,32,33)$. Indeed individuals in our study diagnosed at $\geq 18$ years of age were not obese according to typical BMI cut-offs.

The greater decline in C-peptide observed in patients with a higher BMI could also reflect greater low-grade inflammation associated with obesity $(34,35)$.

In the SEARCH for Diabetes in Youth study, the decline in $\beta$-cell function 12 months after the diagnosis was independent of BMI $z$-score and insulin resistance among autoantibodies-positive patients with diabetes diagnosed at the age of 10-20 years (36). Different to our data, the SEARCH study used a pathogenesis-based approach for the classification of diabetes; furthermore, the SEARCH study included a wide range of racial and ethnic groups and $23 \%$ of the population was not Non-Hispanic White.

Our work may have relevant clinical implications. Although we are not able to define whether insulin resistance or adiposity is the main determinant of the $\beta$-cell decline during the first year after diagnosis, the results presented here may suggest that, especially in individuals diagnosed between 10 and 18 years of age, intervention to reduce insulin resistance (e.g. weight loss) or drugs aimed at improving insulin sensitivity may be a possible component of therapy aimed at preventing fasting C-peptide decline, at least in adolescents. In addition, if the association between BMI and increased $\mathrm{C}$-peptide decline is a result of pro-inflammatory processes associated with obesity, then treatments aimed to reduced inflammation would also be beneficial. Previous studies have shown that with increasing body weight, systemic immune mediators increase not only for type 2 diabetes but also for type 1 diabetes $(37,38)$. Although anti-IL1 therapy was not effective in a post hoc subanalysis of high BMI subjects (39), properly powered and designed studies also testing other anti-inflammatory interventions are needed to determine this question.

Limitations of our study include the reporting of results using untransformed BMI variables for the ease of interpretation and comparison with the data from adults in our cohorts. To overcome this problem, we repeated all analyses with BMI $Z$-score variables and found no difference in results indicating that increased adiposity is likely to underlie this association.

We have used BMI as a proxy for insulin resistance in this study, and although the two variables are strongly related, it would have been preferable to have performed the analysis by directly measuring insulin resistance; however, direct measurement of insulin resistance was not available for analysis. We quantified $\beta$-cell function by analysing $C$-peptide in the fasting state, which may only partially reflect $\beta$-cell function in the stimulated state (e.g. after a meal). Although we did have data on stimulated C-peptide, a limited number of patients had sufficient data for analysis; hence we decided to maximise our sample size by using fasting C-peptide alone as our outcome variable. Data are also limited by the use of different C-peptide assays though all assays had similar detection limits.

Moreover, we did not adjust linear regression models for baseline C-peptide. However, the inclusion of fasting C-peptide at baseline in models is actually a matter of debate in statistical analysis. Thus, we decided not to include it as it may introduce a bias (40).

Another limitation is that diabetes-associated autoimmunity was not evaluated in our study and this parameter appears to be a major variable associated with $\beta$-cell decline, at least in patients $<20$ years of age at diagnosis (36).

In conclusion, our work provides supportive evidence for a key role of body mass in type 1 diabetes disease progression after diagnosis. However, additional studies are needed to define whether insulin resistance or adiposity are key factors leading to $\beta$-cell decline soon after diagnosis of type 1 diabetes.

\section{Declaration of interest}

The authors declare that there is no conflict of interest that could be perceived as prejudicing the impartiality of the research reported.

\section{Funding}

This study was supported by Centro Internazionale Studi Diabete. D Mauricio was supported by a grant from the Instituto Carlos III, Spain (Project FIS 061104).

\footnotetext{
Author contribution statement

A Barker, A Lauria and P Pozzilli were responsible for the design of the study, acquisition of data, analysis and interpretation of data, writing the manuscript and revising it critically for important intellectual content. N Schloot, N Hosszufalusi, J Ludvigsson, C Mathieu, D Mauricio, M Nordwall, B Van der Schueren, T Mandrup-Poulsen, W A Scherbaum, I Weets and $\mathrm{F}$ K Gorus made substantial contributions to the acquisition of data and revised the manuscript critically for important intellectual content. N Wareham made a substantial contribution to the analysis of the data and critical revision of the manuscript for important intellectual content. R D Leslie contributed to discussion and reviewed/edited the manuscript. All authors approved the final version.
} 
diabetes - indication of an increased environmental pressure? Diabetologia 200346 420-425. (doi:10.1007/S00125-003;1045-4)

\section{References}

1 Alberti KG \& Zimmet PZ. Definition, diagnosis and classification of diabetes mellitus and its complications. Part 1: diagnosis and classification of diabetes mellitus provisional report of a WHO consultation. Diabetic Medicine 199815 539-553. (doi:10.1002/ (SICI) 1096-9136(199807)15:7 < 539::AID-DIA668 > 3.0.CO;2-S)

2 Yki-Jarvinen H \& Koivisto VA. Natural course of insulin resistance in type I diabetes. New England Journal of Medicine 1986315 224-230. (doi:10.1056/NEJM198607243150404)

3 Ludvigsson J, Carlsson A, Deli A, Forsander G, Ivarsson SA, Kockum I, Lindblad B, Marcus C, Lernmark Å \& Samuelsson U. Decline of C-peptide during the first year after diagnosis of type 1 diabetes in children and adolescents. Diabetes Research and Clinical Practice 2013 100 203-209. (doi:10.1016/j.diabres.2013.03.003)

4 Wilkin TJ. The accelerator hypothesis: a review of the evidence for insulin resistance as the basis for type I as well as type II diabetes. International Journal of Obesity 200933 716-726. (doi:10.1038/ ijo.2009.97)

5 Ludvigsson J. Why diabetes incidence increases - a unifying theory. Annals of the New York Academy of Sciences 20061079 374-382. (doi:10.1196/annals.1375.058)

6 Onkamo P, Vaananen S, Karvonen M \& Tuomilehto J. Worldwide increase in incidence of type I diabetes - the analysis of the data on published incidence trends. Diabetologia 199942 1395-1403. (doi:10.1007/s001250051309)

7 Johansson C, Samuelsson U \& Ludvigsson J. A high weight gain early in life is associated with an increased risk of type 1 (insulin-dependent) diabetes mellitus. Diabetologia 199437 91-94. (doi:10.1007/ BF00428783)

8 Betts P, Mulligan J, Ward P, Smith B \& Wilkin T. Increasing body weight predicts the earlier onset of insulin-dependant diabetes in childhood: testing the 'accelerator hypothesis' (2). Diabetic Medicine 200522 144-151. (doi:10.1111/j.1464-5491.2004.01368.x)

9 Kordonouri $\mathrm{O} \&$ Hartmann R. Higher body weight is associated with earlier onset of type 1 diabetes in children: confirming the 'Accelerator Hypothesis'. Diabetic Medicine 200522 1783-1784. (doi:10.1111/ j.1464-5491.2005.01792.x)

10 Patterson CC, Dahlquist GG, Gyurus E, Green A, Soltesz G \& Group ES. Incidence trends for childhood type 1 diabetes in Europe during 1989-2003 and predicted new cases 2005-20: a multicentre prospective registration study. Lancet 2009373 2027-2033. (doi:10.1016/S01406736(09)60568-7)

11 Barker A, Lauria A, Schloot N, Hosszufalusi N, Ludvigsson J, Mathieu C, Mauricio D, Nordwall M, Van der Schueren B, Mandrup-Poulsen T et al. Age-dependent decline of $\beta$ cell function in type 1 diabetes after diagnosis: a multi-centre longitudinal study. Diabetes, Obesity \& Metabolism 201316 262-267. (doi:10.1111/dom.12216)

12 Kibirige M, Metcalf B, Renuka R \& Wilkin TJ. Testing the accelerator hypothesis: the relationship between body mass and age at diagnosis of type 1 diabetes. Diabetes Care 200326 2865-2870. (doi:10.2337/ diacare.26.10.2865)

13 Clarke SL, Craig ME, Garnett SP, Chan AK, Cowell CT, Cusumano JM, Kordonouri O, Sambasivan A \& Donaghue KC. Increased adiposity at diagnosis in younger children with type 1 diabetes does not persist. Diabetes Care 200629 1651-1653. (doi:10.2337/dc06-0277)

14 Dabelea D, D'Agostino RB Jr, Mayer-Davis EJ, Pettitt DJ, Imperatore G, Dolan LM, Pihoker C, Hillier TA, Marcovina SM, Linder B et al. Testing the accelerator hypothesis: body size, $\beta$-cell function, and age at onset of type 1 (autoimmune) diabetes. Diabetes Care 200629 290-294. (doi:10.2337/diacare.29.02.06.dc05-1339)

15 Hermann R, Knip M, Veijola R, Simell O, Laine AP, Akerblom HK, Groop PH, Forsblom C, Pettersson-Fernholm K, Ilonen J et al. Temporal changes in the frequencies of HLA genotypes in patients with type 1
16 Gillespie KM, Bain SC, Barnett AH, Bingley PJ, Christie MR, Gill GV \& Gale EA. The rising incidence of childhood type 1 diabetes and reduced contribution of high-risk HLA haplotypes. Lancet 2004364 1699-1700. (doi:10.1016/S0140-6736(04)17357-1)

17 Leslie RD, Taylor R \& Pozzilli P. The role of insulin resistance in the natural history of type 1 diabetes. Diabetic Medicine 199714 327-331. (doi:10.1002/(SICI)1096-9136(199704)14:4<327::AID-DIA315>3.0. $\mathrm{CO} ; 2-6)$

18 Greenbaum CJ. Insulin resistance in type 1 diabetes. Diabetes/Metabolism Research and Reviews 200218 192-200. (doi:10.1002/dmrr.291)

19 Fourlanos S, Narendran P, Byrnes GB, Colman PG \& Harrison LC. Insulin resistance is a risk factor for progression to type 1 diabetes. Diabetologia 200447 1661-1667. (doi:10.1007/s00125-004-1507-3)

20 Fourlanos S, Harrison LC \& Colman PG. The accelerator hypothesis and increasing incidence of type 1 diabetes. Current Opinion in Endocrinology, Diabetes, and Obesity 200815 321-325. (doi:10.1097/MED. 0b013e3283073a5a)

21 Hawa MI, Bonfanti R, Valeri C, Delli Castelli M, Beyan H \& Leslie RD. No evidence for genetically determined alteration in insulin secretion or sensitivity predisposing to type 1 diabetes: a study of identical twins. Diabetes Care 200528 1415-1418. (doi:10.2337/ diacare.28.6.1415)

22 Winkler C, Marienfeld S, Zwilling M, Bonifacio E \& Ziegler AG. Is islet autoimmunity related to insulin sensitivity or body weight in children of parents with type 1 diabetes? Diabetologia 200952 2072-2078. (doi:10.1007/s00125-009-1461-1)

23 Cole TJ. The LMS, method for constructing normalized growth standards. European Journal of Clinical Nutrition 199044 45-60.

24 Poitout V \& Robertson RP. Minireview: secondary $\beta$-cell failure in type 2 diabetes - a convergence of glucotoxicity and lipotoxicity. Endocrinology 2002143 339-342. (doi:10.1210/endo.143.2.8623)

25 Prentki M \& Nolan CJ. Islet $\beta$ cell failure in type 2 diabetes. Journal of Clinical Investigation 2006116 1802-1812. (doi:10.1172/JCI29103)

26 Clausen JO, Borch-Johnsen K, Ibsen H, Bergman RN, Hougaard P, Winther K \& Pedersen O. Insulin sensitivity index, acute insulin response, and glucose effectiveness in a population-based sample of 380 young healthy Caucasians. Analysis of the impact of gender, body fat, physical fitness, and life-style factors. Journal of Clinical Investigation 199698 1195-1209. (doi:10.1172/JCI118903)

27 Wagenknecht LE, Langefeld CD, Scherzinger AL, Norris JM, Haffner SM, Saad MF \& Bergman RN. Insulin sensitivity, insulin secretion, and abdominal fat: the Insulin Resistance Atherosclerosis Study (IRAS) Family Study. Diabetes 200352 2490-2496. (doi:10.2337/diabetes.52. 10.2490)

28 Goran MI \& Gower BA. Longitudinal study on pubertal insulin resistance. Diabetes 200150 2444-2450. (doi:10.2337/diabetes.50.11. 2444)

29 Vandewalle CL, Decraene T, Schuit FC, De Leeuw IH, Pipeleers DG \& Gorus FK. Insulin autoantibodies and high titre islet cell antibodies are preferentially associated with the HLA DQA1*0301-DQB1*0302 haplotype at clinical type 1 (insulin-dependent) diabetes mellitus before age 10 years, but not at onset between age 10 and 40 years. The Belgian Diabetes Registry. Diabetologia 199336 1155-1162. (doi:10.1007/BF00401060)

30 Awata T, Hagura R, Urakami T \& Kanazawa Y. Age-dependent HLA, genetic heterogeneity of IDDM in Japanese patients. Diabetologia 1995 38 748-749. (doi:10.1007/BF00401850)

31 Graham J, Kockum I, Sanjeevi CB, Landin-Olsson M, Nystrom L, Sundkvist G, Arnqvist H, Blohme G, Lithner F, Littorin B et al. Negative association between type 1 diabetes and HLA DQB1*0602-DQA1*0102 is attenuated with age at onset, Swedish Childhood Diabetes Study Group. European Journal of Immunogenetics 199926 117-127. (doi:10.1046/j.1365-2370.1999.00127.x-i2) 
32 Howson JM, Rosinger S, Smyth DJ, Boehm BO, Group A-ES \& Todd JA. Genetic analysis of adult-onset autoimmune diabetes. Diabetes 201160 2645-2653. (doi:10.2337/db11-0364)

33 Lohmann T, Sessler J, Verlohren HJ, Schroder S, Rotger J, Dahn K, Morgenthaler N\& Scherbaum WA. Distinct genetic and immunological features in patients with onset of IDDM before and after age 40. Diabetes Care 199720 524-529. (doi:10.2337/diacare.20.4.524)

34 Ferrante AW Jr. Obesity-induced inflammation: a metabolic dialogue in the language of inflammation. Journal of Internal Medicine 2007262 408-414. (doi:10.1111/j.1365-2796.2007.01852.x)

35 Shoelson SE, Herrero L \& Naaz A. Obesity, inflammation, and insulin resistance. Gastroenterology 2007132 2169-2180. (doi:10.1053/j.gastro. 2007.03.059)

36 Dabelea D, Mayer-Davis EJ, Andrews JS, Dolan LM, Pihoker C, Hamman RF, Greenbaum C, Marcovina S, Fujimoto W, Linder B et al. Clinical evolution of $\beta$ cell function in youth with diabetes: the SEARCH for Diabetes in Youth study. Diabetologia 201255 3359-3368. (doi:10.1007/s00125-012-2719-6)

37 Pham MN, Hawa MI, Roden M, Schernthaner G, Pozzilli P, Buzzetti R, Scherbaum WA, Seissler J, Hunter S, Leslie RD et al. Increased serum concentrations of adhesion molecules but not of chemokines in patients with type 2 diabetes compared with patients with type 1 diabetes and latent autoimmune diabetes in adult age: action LADA 5. Diabetic Medicine 201229 470-478. (doi:10.1111/j.1464-5491.2011. 03546.x)

38 Pham MN, Hawa MI, Pfleger C, Roden M, Schernthaner G, Pozzilli P, Buzzetti R, Scherbaum W, Seissler J, Kolb H et al. Pro- and antiinflammatory cytokines in latent autoimmune diabetes in adults, type 1 and type 2 diabetes patients: action LADA 4. Diabetologia 2011 54 1630-1638. (doi:10.1007/s00125-011-2088-6)

39 Moran A, Bundy B, Becker DJ, DiMeglio LA, Gitelman SE, Goland R, Greenbaum CJ, Herold KC, Marks JB, Raskin P et al. Interleukin-1 antagonism in type 1 diabetes of recent onset: two multicentre, randomised, double-blind, placebo-controlled trials. Lancet 2013381 1905-1915. (doi:10.1016/S0140-6736(13) 60023-9)

40 Glymour MM, Weuve J, Berkman LF, Kawachi I \& Robins JM. When is baseline adjustment useful in analyses of change? An example with education and cognitive change. American Journal of Epidemiology 2005 162 267-278. (doi:10.1093/aje/kwi187)
Received 7 July 2014

Revised version received 15 October 2014

Accepted 6 November 2014 